ISSN 2525-4804

\title{
DESEMPENHO AGRONÔMICO DE VARIEDADES DE MANDIOCA EM SISTEMA IRRIGADO
}

\author{
Esdras Henrique da Silva ${ }^{1}$, Daniel Santana Colares ${ }^{1}$, Raimundo Filho Freire Brito ${ }^{2}$, Vitória Eduarda \\ Ferreira $^{3}$, Antônio Jocely Saraiva da Silva Junior ${ }^{3}$, Gustavo Azevedo Campos ${ }^{4}$
}

\section{RESUMO:}

Este trabalho teve como objetivo avaliar a produtividade e adaptação das variedades de mandioca ARN, BRS 399, BRS 400, BRS 401 e Cacau na região norte do estado do Tocantins em sistema irrigado. O ensaio foi conduzido na área experimental do Instituto Federal do Tocantins (IFTO), campus Colinas do Tocantins. O delineamento utilizado foi em blocos casualizados, sendo os tratamentos as variedades de mandiocas mencionadas, com quatro repetições. Cada repetição apresentou quatro linhas de dez plantas, sendo que a parcela experimental útil foi composta pelas duas linhas centrais, na qual avaliou-se as cinco plantas centrais de cada linha útil. O manejo de irrigação adotado foi o de fitas gotejadoras. Foram realizadas três adubações e a avaliação ocorreu nove meses após o plantio. As variáveis avaliadas foram: altura da planta e da primeira bifurcação, massa da parte aérea, massa das raízes tuberosas (produtividade das raízes), índice de colheita, tempo de cocção, teor de amido e rendimento de farinha. Os resultados evidenciaram a existência de diferenças significativas, entre as cinco variedades testadas, para os parâmetros altura da planta e da primeira ramificação, massa da parte aérea, produtividade de raízes e tempo de cocção. Todas as variedades obtiveram produtividade satisfatória, sendo que a BRS 401, BRS 400 e a BRS 399 destacaram-se por apresentar 61,26, 52,34 e 49,70 t/ha, respectivamente. As variedades Cacau, ARN e BRS 401 apresentaram os menores tempo de cocção, 16, 17 e 18,5 minutos, respectivamente. O genótipo BRS 401 apresentou maior altura de planta, e da primeira ramificação, maiores produtividades de raiz (61,26 t/ha) e da parte aérea (30,97 t/ha). De modo geral, todas as variedades apresentaram resultados satisfatórios e podem ser recomendadas para o plantio na região norte do Tocantins.

Palavras-chave: Manihot esculenta, produtividade, Tocantins.

\footnotetext{
${ }^{1}$ Professor do Instituto Federal do Tocantins (IFTO), campus Colinas do Tocantins, Brasil. E-mails: esdras.silva@ifto.edu.br e daniel.colares@ifto.edu.br

2 Doutorando em Ciência Animal Tropical, Universidade Federal do Norte do Tocantins (UFNT), Brasil. E-mail: raimundofreire76@gmail.com

3 Discente do curso de Engenharia Agronômica do IFTO de Colinas do Tocantins, Brasil. E-mails: vitoria.ferreira@estudante.ifto.edu.br e jocely470@gmail.com

${ }^{4}$ Pesquisador da Embrapa Pesca, Aquicultura e Sistemas Agrícolas, NSA - Núcleo de Sistemas Agrícolas, Palmas - TO, Brasil. Email: gustavo.campos@embrapa.br
} 
ISSN 2525-4804

\title{
AGRONOMIC PERFORMANCE OF CASSAVA VARIETIES IN IRRIGATED SYSTEM
}

\begin{abstract}
:
This study aimed to evaluate the productivity and adaptation of the cassava varieties BRS 399, BRS 400, BRS 401, Cacau, and ARN in the north of the state of Tocantins in irrigated system. The experiment was conducted in the experimental area of the Federal Institute of Tocantins (IFTO), Colinas do Tocantins campus. The design used was randomized blocks, the treatments were the varieties of cassava mentioned before, with four replications. Each replication had four rows of ten plants, the useful experimental plot was composed of the two central rows, in which the five central plants of each row were evaluated. Irrigation management used was the drip tapes. Three fertilizations were performed and the evaluations occurred nine months after planting. Plant height, the first bifurcation height, shoot mass, storage roots (root productivity), harvest index, cooking time, amount of starch and flour yield were the variables evaluated. The results presented significant differences among the five varieties tested for plant height and the first bifurcation height, shoot mass, root productivity and cooking time. All varieties obtained satisfactory productivity, with BRS 401, BRS 400, and BRS 399 had the highest yield, 61.26, 52.34, and 49.70 t/ha, respectively. The Cacau, ARN, and BRS 401 had the shortest cooking time, 16, 17, and 18.5 minutes, respectively. The BRS 401 variety was the one that obtained the highest plant height, the first bifurcation height, root productivity (61.26 t/ha), and shoot mass (30.97 t/ha). In general, all varieties tested showed promising results and can be recommended for planting in the north of the state of Tocantins.
\end{abstract}

Key words: Manihot esculenta, productivity, Tocantins. 


\section{INTRODUÇÃO}

A mandioca, também conhecida como macaxeira ou aipim, é amplamente utilizada na alimentação, especialmente Manihot esculenta Crantz (Euphorbiaceae) (Fialho e Vieira, 2011). É considerada uma espécie rústica por adaptar-se em diferentes condições climáticas e em solos com baixa fertilidade, resistir a períodos longos de seca e não necessitar de manejo intenso (FAO, 2013). A raiz é o principal órgão de interesse (utilizada na alimentação seja in natura ou industrial), e sua colheita ocorre entre 8 a 18 meses após o plantio (Modesto Junior e Alves, 2014). A produção brasileira de mandioca, em sua grande parte, é feita por pequenos produtores que movimentam as economias locais e abastecem os mercados regionais e feiras livres (Valle e Lorenzi, 2014).

No cenário mundial, a Nigéria é o maior produtor de mandioca, seguida por Tailândia, Indonésia, Brasil, República Democrática do Congo e Gana, que juntos são responsáveis por $60 \%$ da produção mundial. O Brasil produz 20,60 milhões de toneladas, sendo Pará, Paraná, São Paulo, Rio Grande do Sul e Amazonas os maiores produtores (CONAB, 2018). O estado do Tocantins é o $18^{\circ}$ produtor (225.763 toneladas) com área plantada de 14.396 hectares e produtividade média de 15.704 $\mathrm{kg} / \mathrm{ha}$ (IBGE, 2019). O gargalo da mandiocultura (não apenas no Tocantins, mas em todo território nacional), é a baixa produtividade, principalmente dos pequenos produtores. Com ajustes no manejo utilizado, o uso de variedades melhoradas e adaptadas aos diversos tipos de clima e solo brasileiro a produtividade dessa cultura aumentará consideravelmente (Fialho et al., 2009; Seba et al., 2017).

Nos últimos 40 anos, a mandiocultura passou por um grande processo de modernização para adaptar-se às exigências do mercado (Valle e Lorenzi, 2014). A sua longa história de domesticação e adaptação ecológica, assim como a diversidade de uso, produziu um grande número de variedades adaptadas a condições edafoclimáticas diferentes. A mandioca é cultivada em ambientes tropicais de solos típicos, de pouca fertilidade, alto teor de alumínio e reduzida disponibilidade de nutrientes (Howeler, 1981). Além disso, tolera desde altas precipitações, como na região Amazônica, até as deficiências hídricas do semiárido brasileiro. O Brasil é o centro de domesticação e possui a maior reserva genética de M. esculenta, e a incorporação desses genes nos programas de melhoramento realizados pela Embrapa vem proporcionando o surgimento de variedades mais produtivas e adaptadas aos diversos tipos de clima e solo (Fialho e Vieira, 2011). Neste sentido, tem-se focado na seleção de variedades de raízes de polpa amarela e rosada, que são ricas em carotenoides e licopenos, respectivamente (Silva et al., 2014).

Em 2015, a Embrapa Cerrados lançou duas variedades de mandioca de polpa rosada, a BRS 400 e BRS 401. Esses genótipos apresentaram alta produtividade e boa aceitação pelos produtores da região do Distrito Federal (Vieira et al., 2019), o que as tornam uma opção para a população, além de agregar valor aos produtos gerados. Contudo, a introdução de novas cultivares depende de testes de produtividade e aceitação pelo público consumidor. Dessa forma, o objetivo desse trabalho foi avaliar o potencial agronômico de cinco variedades de mandioca de mesa (BRS 399, BRS 400, BRS 401, Cacau e ARN) em sistema de cultivo irrigado nas condições edafoclimáticas do norte do estado do Tocantins.

\section{MATERIAL E MÉTODOS}

O experimento foi conduzido em Colinas do Tocantins, na fazenda Experimental do IFTO (coordenadas 0809'37" S, 48 47'79" W e 227 m de altitude), no período de 22 de fevereiro a 27 de novembro de 2019. O clima da região, de acordo com a classificação de Köppen, é do tipo Aw (clima tropical com estação seca de inverno) com temperatura média anual de $27,16{ }^{\circ} \mathrm{C}$. O período 
chuvoso ocorre, notadamente, de novembro a maio, e o mais seco de junho a outubro. O solo da área é do tipo Neossolo Quartzarênico com pH de 5,6.

Para a realização deste trabalho, foram adotadas as técnicas do Trio da Produtividade da mandioca, que consiste na seleção e corte reto de manivas-sementes, plantio no espaçamento de 1,0 m x 1,0 m, e controle de plantas infestantes durante 150 dias após o plantio da cultura (Modesto Junior e Alves, 2014).

O delineamento experimental foi em blocos casualizados com quatro repetições e cinco tratamentos (variedades ARN, BRS 399, 400, $401 \mathrm{e}$ Cacau). Cada repetição apresentou quatro linhas de dez plantas, sendo que a parcela experimental útil foi composta pelas duas linhas centrais, na qual avaliou-se as cinco plantas centrais de cada linha útil, totalizando uma área de $160 \mathrm{~m}^{2} /$ variedade.

Para a adubação de plantio, foram aplicados $50 \mathrm{~g}$ do fertilizante supersimples $\left(18 \% \mathrm{P}_{2} \mathrm{O}_{5}\right)$ por cova. Aos 40 e 70 dias após o plantio, foi realizada a adubação de cobertura utilizando $40 \mathrm{~g}$ do fertilizante por cova, nas respectivas épocas, com a formulação 20-0-20. A irrigação ocorreu diariamente no período de déficit hídrico, sendo o volume de água fornecido correspondente ao da evapotranspiração de referência (ETo). O cálculo da ETo diária foi feito pelo método de PenmanMonteith, recomendado pela Faostat (Smith et al., 1991), utilizando os dados diários de temperatura máxima e mínima, umidade relativa do ar, insolação e velocidade do vento obtidos pela estação meteorológica automática do INMET, localizada no IFTO de Colinas do Tocantins. A irrigação utilizada foi a de fita gotejadora de $2,5 \mathrm{~L} / \mathrm{h}$, sendo uma fita gotejadora por linha de cultivo.

Nove meses após o plantio, foram realizadas as seguintes avaliações: altura das plantas (AP) - a partir do nível do solo até a extremidade mais alta da planta; altura da primeira ramificação - a partir do nível do solo até a primeira ramificação ou bifurcação; massa da parte aérea (MPA) em t/ha, = produtividade da parte aérea; massa das raízes tuberosas (MRT) t/ha (produtividade de raiz); e índice de colheita (IC) - relação expressa em \% entre o peso das raízes tuberosas e o peso total da planta. Estes valores foram obtidos das 10 plantas da parcela útil de cada repetição e as aferições foram feitas com uma balança portátil de gancho digital que pesa até $50 \mathrm{~kg}$.

A cocção da raiz foi avaliada mediante aferição do tempo. Para tanto, pedaços de $5 \mathrm{~cm}$ de raízes foram retirados do terço médio de cada repetição e colocados em 1 litro de água em ebulição. Em intervalos de 5 minutos, os pedaços de raízes eram espetados com um garfo para verificar o grau de cozimento e determinar o tempo de cocção. Esse procedimento foi realizado individualmente para cada repetição. As mandiocas foram consideradas cozidas quando ofereceram pouca resistência à penetração perpendicular do garfo em relação ao comprimento, sendo verificadas sempre pelo mesmo avaliador (adaptado de Borges et al., 2002). A cocção foi considerada adequada quando o cozimento da polpa ocorreu em no máximo 30 minutos após a imersão na água fervente (Wheatley, 1987).

As variáveis relacionadas à qualidade industrial foram avaliadas pelo método da balança hidrostática (Grossman e Freitas, 1950), pesando-se $3 \mathrm{~kg}$ de raiz do terço médio de cada repetição e aferição do peso após submersão em água. $\mathrm{O}$ teor de massa seca (\%) foi estimado pela equação: MS (\%) $=15,75+0,0564 \mathrm{R}$, sendo $\mathrm{R}$ o peso de $3 \mathrm{~kg}$ de raízes em água; o teor de amido da raiz (AR) estimado foi: MS - 4,65; e a porcentagem de rendimento de farinha (RF) foi estimado com base na fórmula proposta por Fukuda e Caldas (1987): $\mathrm{RF}=2,56576$ $+0,0751613564 \mathrm{R}$.

Os dados foram submetidos a análise de variância para a comparação das médias e havendo significância para o teste $\mathrm{F}$, realizou-se o teste de Tukey a $5 \%$ de probabilidade, utilizando o programa estatístico Sisvar (Ferreira, 2011). 


\section{RESULTADOS E DISCUSSÃO}

Houve diferença significativa para a variável IC (Tabela 1), na qual a variedade BRS 399 $(71,40 \%)$ foi estatisticamente superior a variedade Cacau $(58,95 \%)$, e igual as variedades BRS 400 $(65,40 \%)$, BRS $401(66,47 \%)$ e ARN $(66,53 \%)$. O IC mostra a eficiência das variedades na produção de raízes, identificando aquelas que apresentam maior capacidade de direcionar os carboidratos produzidos nas folhas para a produção de raízes. De acordo com Peixoto et al. (2005), o IC é considerado satisfatório quando for superior a 50\%. Dessa forma, todas as variedades deste trabalho apresentaram valores satisfatórios.

Tabela 1 -Médias das porcentagens das variáveis de amido da raiz (AR), índice de colheita (IC), rendimento de farinha (RF) e tempo de cocção (TC) avaliadas em cinco variedades de mandioca de mesa. Colinas do Tocantins (TO), 2019.

\begin{tabular}{ccccc}
\hline Variedade & AR (\%) & IC (\%) & RF (\%) & TC (min) \\
\hline Cacau & $30,99 \mathrm{a}$ & $58,95 \mathrm{~b}$ & $29,35 \mathrm{a}$ & $16,25 \mathrm{a}$ \\
BRS 400 & $32,39 \mathrm{a}$ & $65,40 \mathrm{ab}$ & $30,92 \mathrm{a}$ & $27,50 \mathrm{~b}$ \\
BRS401 & $30,85 \mathrm{a}$ & $66,47 \mathrm{ab}$ & $29,05 \mathrm{a}$ & $17,25 \mathrm{a}$ \\
ARN & $31,04 \mathrm{a}$ & $66,53 \mathrm{ab}$ & $29,07 \mathrm{a}$ & $17,25 \mathrm{a}$ \\
BRS399 & $27,95 \mathrm{a}$ & $71,40 \mathrm{a}$ & $25,02 \mathrm{a}$ & $25,00 \mathrm{~b}$
\end{tabular}

Médias seguidas por diferentes letras minúsculas em uma mesma coluna indicam diferença significativa pelo deste de Tukey a 5\% de significância.

Paz et al. (2020) avaliaram o IC das variedades BRS 399, 400 e 401 em duas safras seguidas, sendo que na primeira e segunda avaliação (safra) a variedade BRS 399 apresentou o maior IC, $60 \%$ e $58 \%$, respectivamente. Entretanto, as variedades BRS 400 e BRS 401 apresentaram valores de IC abaixo de $50 \%$ na segunda safra. Tal fato, provavelmente ocorreu devido ao déficit hídrico, pois o experimento foi conduzido em sistema de sequeiro.

Com relação a cocção, todas as variedades apresentaram tempo menor que 30 minutos (Tabela1). As variedades ARN, BRS 401 e Cacau cozinharam com tempo médio inferior a 18 minutos, diferindo estatisticamente das variedades BRS 399 e 400, que precisaram de um tempo igual ou superior a 25 minutos para a cocção. Segundo Rinaldi et al. (2015), as variedades BRS 399 e BRS 400 requerem um tempo maior de cocção, o que pode ser uma característica intrínseca desses genótipos. O tempo considerado ideal para a cocção das raízes de mandioca deve ser entre 15 e 25 minutos (Lorenzi, 2003; Borges et al., 2002).

Os valores médios de porcentagem de AR e RF não diferiram estatisticamente entre as cinco variedades (Tabela 1). Apesar de possuírem aptidão principal para produção de raízes para mesa, o potencial destas variedades em relação a produção de farinha não deve ser negligenciado, pois na falta de compradores ou mercado para a comercialização da mandioca in natura a produção de farinha é uma opção para estocar a produção e ganhar tempo para futuras negociações e comercializações. Neste sentido, observou-se que as variedades BRS $401 \mathrm{e}$ BRS 400 são promissoras para a produção de farinha, pois obtiveram produção de 356 e 324 sacos de farinhas por hectare, respectivamente. As variedades BRS 399, Cacau e ARN produziriam, 
respectivamente 249, 226 e 209 sacos de farinha, valores bem inferiores que os outros genótipos.

Verificando a figura 1, observa-se que houve diferença estatística entre as variáveis altura da planta (AP) e altura da primeira bifurcação. A variedade BRS 401 apresentou maior AP $(2,81 \mathrm{~m})$, diferenciando estatisticamente das variedades ARN (2,27 m), Cacau (2,24 m), BRS 400 (2,21 m) e BRS $399(1,98 \mathrm{~m})$. Em relação a variável altura da primeira bifurcação, houve diferença estatística entre as cinco variedades. A maior altura de bifurcação foi observada no genótipo ARN (2,10 $\mathrm{m})$, que diferenciou estatisticamente dos demais. As variedades BRS 399 (0,52 m) e BRS 400 (0,62 m) apresentaram os menores valores, que não diferiram estatisticamente entre si, mas sim dos demais genótipos.

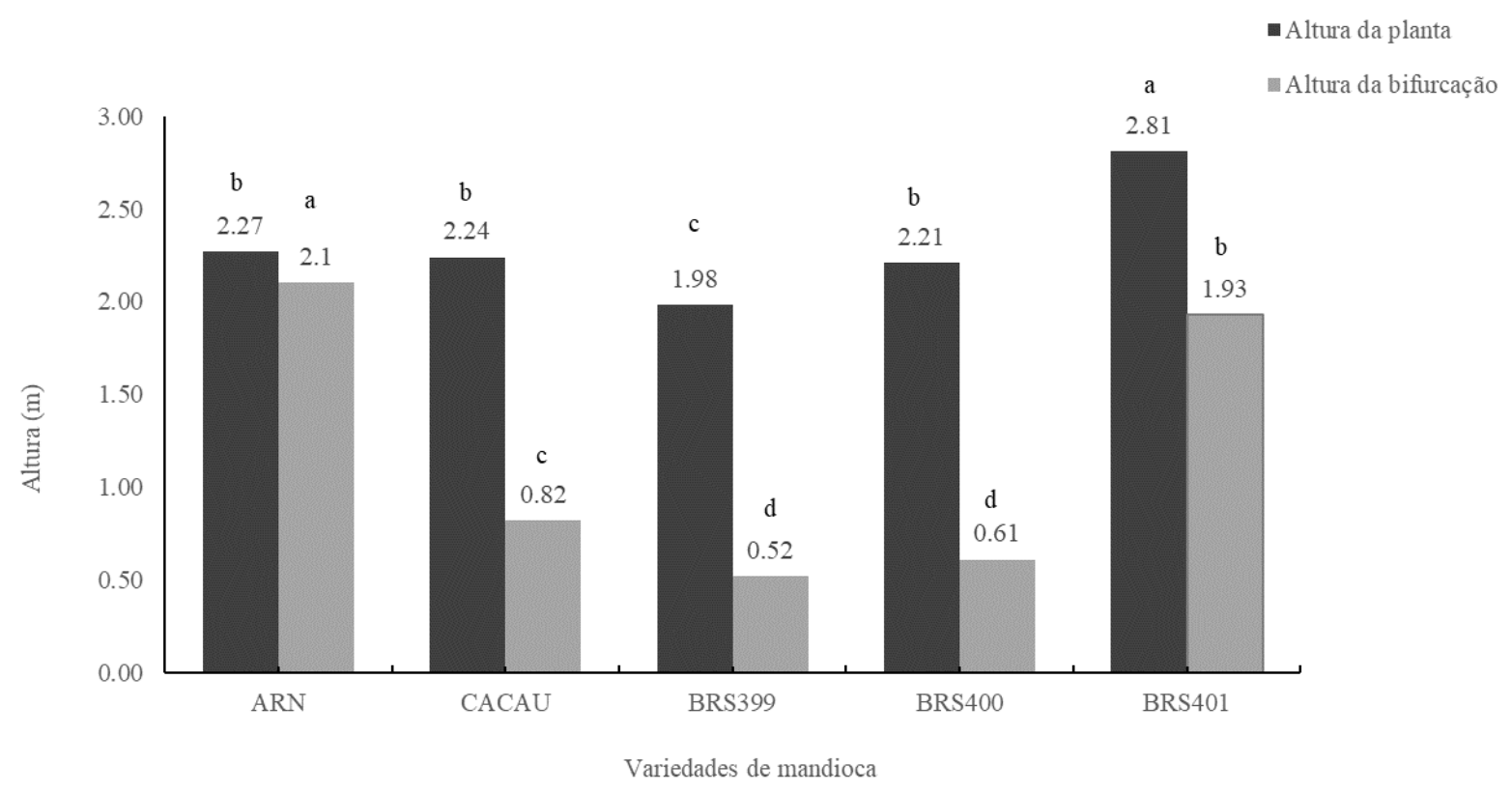

Figura 1. Altura da planta e altura da primeira bifurcação das cinco variedades de mandioca testadas. Médias seguidas por diferentes letras minúsculas em uma mesma cor indicam diferença significativa pelo deste de Tukey a 5\% de significância.

A AP é um parâmetro importante para a determinação do espaçamento, escolha de variedades que poderão ser usadas em consórcio e na competição com plantas daninhas (Rós et al., 2011). Nesse sentido, as variedades ARN e BRS 401 (maiores valores de AP e de primeira ramificação) apresentam uma ótima cobertura e sombreamento do solo que diminuem as infestações por plantas indesejáveis. Além disso, esses dois genótipos são promissores no fornecimento de manivas-sementes para plantio mecanizado, pois quanto maior a rama maior é o rendimento operacional da plantadeira (Fialho et al., 2009; Vidigal Filho et al., 2000; Azevedo et al., 2006). A variedade BRS 399 apresentou um baixo rendimento de manivas-sementes, além de dificultar os tratos culturais como capina e adubação (Fukuda et al., 2002). A variedade BRS 400, apesar de possuir uma baixa altura da primeira bifurcação (Figura 1), foi a segunda variedade a ter os maiores valores de AP e MPA, o que aumenta sua produção de manivas-sementes.

Na avaliação dos parâmetros produtividade de raiz e da parte aérea, foi observada diferença estatística (Figura 2). A variedade BRS 401 obteve o maior valor de produção de raiz $(61,26 \mathrm{t} / \mathrm{ha}) \mathrm{e}$ MPA (30,97 t/ha). Quando se compara a produtividade de raiz desta variedade com os genótipos BRS 400 (52,34 t/ha) e BRS 399 (49,70 t/ha), observa-se que não houve diferença 
significativa entre os valores encontrados. Em contrapartida, as variedades ARN e Cacau apresentaram valores significativamente diferentes ao de BRS 401. A variedade ARN apresentou a menor produtividade de raiz (Figura 2) dentre os cinco genótipos estudados, porém não diferiu estatisticamente das variedades Cacau (38,50 t/ha) e BRS 399 (49,70 t/ha). Em relação a produtividade da parte aérea, as variedades BRS 401 (30,97 t/ha), BRS 400 (27,38 t/ha) e Cacau (26,66 t/ha) não apresentaram diferenças significativas entre si, mas sim entre as variedades BRS 399 (19,86 t/ha) e ARN $(17,65 \mathrm{t} / \mathrm{ha})$. Ao comparar a produtividade da parte aérea entre a BRS 401 e as variedades BRS 399 e ARN, observa-se que a BRS 401 produziu, respectivamente, $35 \%$ e $43 \%$, mais massa da parte aérea, demostrando um alto potencial de uso para a alimentação de animais ruminantes como ovinos e bovinos (Souza et al., 2012).

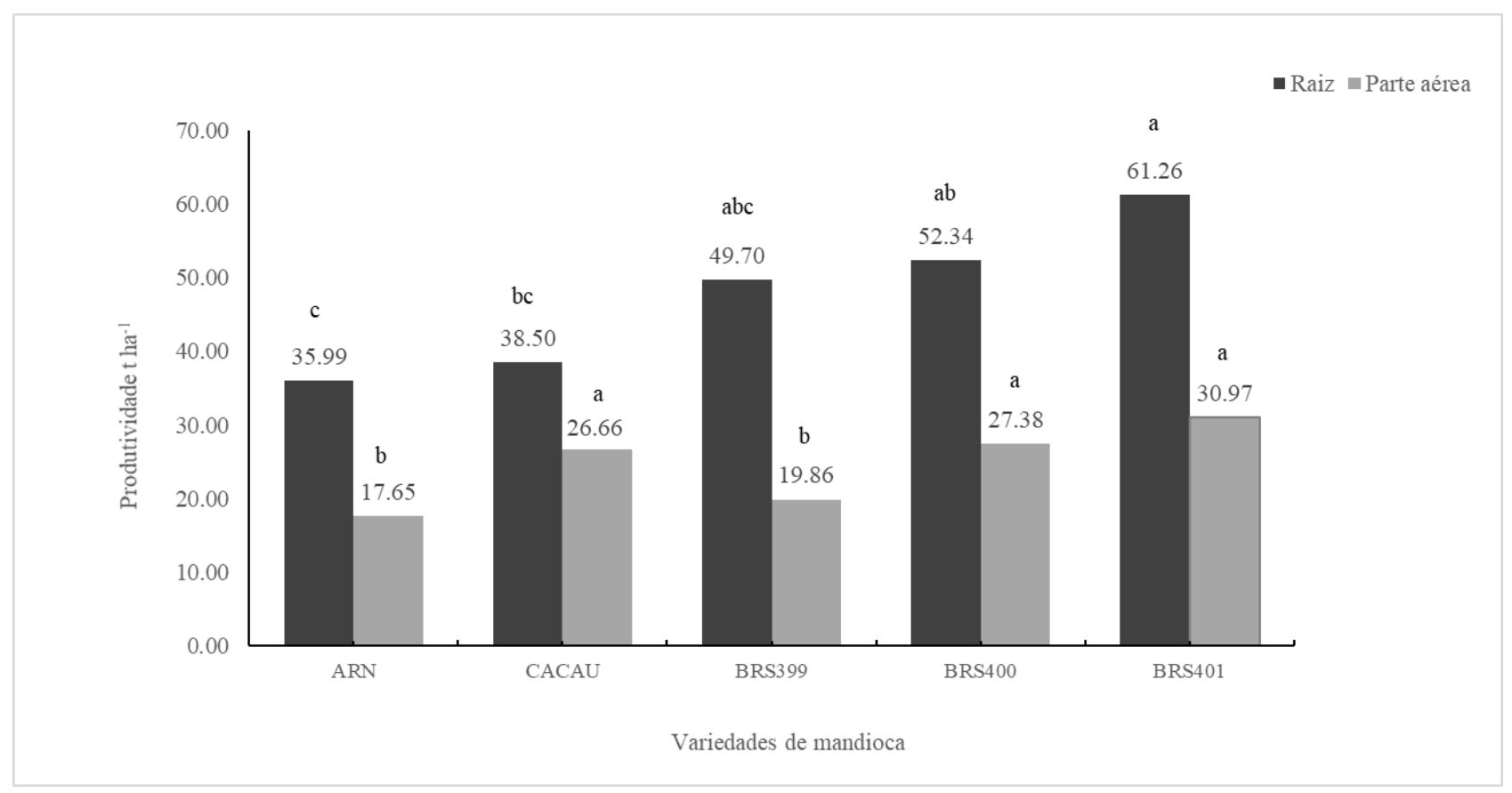

Figura 2. Médias da produtividade de raiz e produtividade da parte aérea das cinco variedades de mandioca testadas. Médias seguidas por diferentes letras minúsculas em uma mesma cor indicam diferença significativa pelo deste de Tukey a 5\% de significância.

Trabalhos recém-publicados corroboram com os dados de produtividade de raiz aqui encontrados. Em estudo realizado no campo experimental da Universidade Estadual de Goiás, na cidade de Ipameri, Matos et al. (2016) avaliaram o comportamento de quatro variedades (BRS 396, 397, 398 e 399) de mandioca em sistema irrigado, na qual a variedade BRS 399 alcançou produtividade de 47,18 t/ha. Paz et al. (2020) realizaram um experimento na cidade de Jataí-GO e verificaram que a variedade BRS 399 produziu 58 t/ha de raiz em duas safras seguidas. Menezes et al. (2019) avaliaram a produtividade de cinco variedades de mandioca na cidade de Montes Claros-MG, e verificaram que a Cacau produziu 38,18 t/ha. Ao comparar os resultados dos autores mencionados com os obtidos neste trabalho, observa-se que as variedades BRS 399 e Cacau obtiveram alta produtividade de raiz em diferentes regiões. 
É importante mencionar que as variedades BRS 400 e BRS 401 não tiveram altas produtividades quando avaliadas dez meses após o plantio sem uso de irrigação, em duas safras consecutivas, na cidade de Jataí-GO (Paz et al., 2020). A variedade BRS 401 apresentou a menor produtividade, 27,93 t/ha na primeira safra $(2016 / 17)$ e $25,53 \mathrm{t} /$ ha na segunda (2017/18). Ao comparar a produtividade de raiz da variedade BRS 401 obtida no trabalho de Paz et al. (2020) com a produtividade deste trabalho (Figura 2), observa-se uma diferença de $33 \mathrm{t} / \mathrm{ha}$. Pode ser que os diferentes tipos de manejo (sequeiro e irrigado, respectivamente) e de solo (Latossolo e Neossolo Quartzarênico, de modo respectivo) dos estudos expliquem esta diferença, haja vista que o clima das duas regiões é semelhante.

Levando em consideração a alta produção das variedades BRS 401, BRS 400 e BRS 399, o próximo passo seria avaliar a aceitação dessas variedades pelo consumidor final. É importante salientar a alta produtividade de raiz e parte aérea da variedade BRS 401, além de seu alto rendimento na produção de farinha. Essa variedade é de fácil manejo e, juntamente com a ARN, apresentou maior altura da primeira ramificação.

\section{CONCLUSÃO}

Todas as variedades testadas nesse trabalho podem ser plantadas na região norte do Tocantins em sistema irrigado. Porém, a variedade BRS 401 demonstrou ser mais adequada por possuir uma alta produção de raiz e de parte aérea, além de alto rendimento de farinha.

\section{AGRADECIMENTOS}

Agradecemos ao pesquisador Dr. Gustavo Azevedo Campos da Embrapa Pesca e Aquicultura pelo fornecimento das ramas usadas para realização deste trabalho.

\section{REFERÊNCIAS BIBLIOGRÁFICAS}

Azevedo, E.B.; Nörnberg, J.L.; Kessler, J.D.; Brüning, G.; David, D.B.; Falkenberg, J.R.; Chielle, Z.G. (2006). Silagem da parte aérea de cultivares de mandioca. Ciência Rural 36(1): 1902-1908. http://dx.doi.org/10.1590/S0103$\underline{84782006000600037}$

Borges, M.F.; Fukuda, W.M.G.; Rossetti, A.G. (2002). Avaliação de variedades de mandioca para consumo humano. Pesquisa Agropecuária Brasileira 37(11): 1559-1565.

http://dx.doi.org/10.1590/S0100$\underline{204 X 2002001100006}$

CONAB. (2018). Companhia Nacional de Abastecimento. Análise mensal fevereiro 2018. Brasília-DF.

FAO. (2013). Produzir mais com menos: Mandioca - Um guia para a intensificação sustentável da produção. (Informe de Política), Rome.

Ferreira, D.F. (2011). Sisvar: A computer statistical analysis system. Ciência e Agrotecnologia 35(6): 1039-1042.

Fialho, J.F.; Andrade, R.F.R.; Vieira, E.A. (2009). Mandioca no cerrado: questões práticas. $1^{\circ} \mathrm{ed}$. Planaltina: Embrapa Cerrados. 87p.

Fialho, J.F.; Vieira, E. A. (2011). Mandioca no cerrado. Planaltina: Embrapa Cerrados. 208p.

Fukuda, W.M.G.; Caldas, R.C. (1987). Relação entre os conteúdos de amido e farinha de mandioca. Revista Brasileira de Mandioca 6(1): 57-63.

Fukuda, W.M.G.; Silva, S.O.; Iglesias, C. (2002). Cassava breeding. Crop Breeding and Applied Biotechnology 2(4): 617-638. 
Grossman, J.; Freitas, A.G. (1950). Determinação do teor de matéria seca pelo método do peso específico em raízes de mandioca. Revista Agronômica 14(1): 75-80.

Howeler, H. (1981). Mineral nutrition and fertilization of cassava (Manihot esculenta Crantz). Cali: Centro Internacional de Agricultura Tropical. $52 \mathrm{p}$.

IBGE. (2019). Instituto Brasileiro de Geografia Estatística. Disponível em: http://cidades.ibge.gov.br/brasil/to/pesquisa/14/101 93?tipo=ranking\&indicador $=10335 \&$ ano $=2019$

Lorenzi, J.O. (2003). Mandioca. Boletim técnico. CATI. 110p.

Matos, F.S.; Felicio, R.; Silveira, P.S.; Guimarães, R.R.; Santos, P.G.F.; Nascente, A.C.S.; Custódio, J.P.C.; Silva, L.M. (2016). Produtividade de cultivares de mandioca sob déficit hídrico. AgriEnvironment Sciences 2(1): 15-24.

Menezes, J.B.C.; Catão, H.C.R.M.; Costa, C.A.; Chauca, M.N.C. (2019). Aspectos agronômicos e qualidade de raízes de mandioca minimamente processadas. Revista Agrarian 12(46): 425-433.

Modesto Junior, M.S.; Alves, N.B. (2014). Cultura da mandioca: apostila. Belém: Embrapa Amazônica Oriental. 197p.

Paz, R.B.O.; Costa, C.H.M.; Vieira, E.A.; Coelho, M.V.; Cruz, S.C.S.; Machado, L.B. (2020). Desempenho agronômico de cultivares de mandioca de mesa em ambiente do cerrado. Colloquium Agrariae 16(3): 37-47.

Peixoto, J.R.; Bernardes, S.R.; Santos, C.M.; Bonnas, D.S.; Fialho, J. de. F.; Oliveira, J.A. (2005). Desempenho agronômico de variedades de mandioca mansa em Uberlândia, MG. Revista Brasileira de Mandioca 18(1): 19-24.
Rinaldi, M.M.; Vieira, E.A.; Fialho, J.F. (2015). Conservação pós-colheita de diferentes cultivares de mandioca submetidas ao processamento mínimo e congelamento. Científica 43(4): 287-301. http://dx.doi.org/10.15361/1984-

$\underline{5529.2015 v 43 n 4 p 287-301}$

Rós, A.B.; Hirata, A.C.S.; Araújo, H.S.; Narita, N. (2011). Crescimento, fenologia e produtividade de cultivares de mandioca. Pesquisa Agropecuária Tropical 41(4): 552-558.

Seba, G.A.; Loures, H.S.; Yamashita, O.M.; Roboredo, D.; Carvalho, M.A.C.; Parente, T.L.; Caioni, S. (2017). Produtividade de variedades de mandioca no município de Alta Floresta - MT, localizada no portal da Amazônia Brasileira. Revista Cultivando o Saber 10(1): 68-81.

Silva, K.N.; Vieira, E.A.; Fialho, J.F.; Carvalho, L.J.C.B.; Silva, M.S. (2014). Potencial agronômico e teor de carotenoides em raízes de reserva de mandioca. Ciência Rural 44(8): 1348-1354. http://dx.doi.org/10.1590/0103-8478cr20130606

Smith, M. (1991). Report on the expert consultation on revision of FAO methodologies for crop water requirements. Rome: FAO. 45p.

Souza, A.S.; Rocha Júnior, V.R.; Mota, A.D.S.; Rocha, W.J.B.; Oliviera, C.R.; Aguiar, A.C.R.; Santos, C.C.R.; Mendes, G.A. (2012). Potencial forrageiro e valor nutricional do feno de diferentes frações da parte aérea de quatro variedades de mandioca. Revista Brasileira de Saúde e Produção Animal 13(3): 604-618.

Valle, T.L.; Lorenzi, J.O. (2014). Variedades melhoradas de mandioca como instrumento de inovação, segurança alimentar, competitividade e sustentabilidade: contribuições do instituto agronômico de campinas (IAC). Cadernos de Ciência \& Tecnologia 31(1): 15-34. 
Vidigal Filho, P.S.; Pequeno, M.G.; Scapim, C.A.; C.M.; Fernandes, F.D.; Anjos, J.R.N. (2019). BRS Vidigal, M.C.G.; Maia, R.R.; Sagrilo, E.; Simon, 400 and BRS 401, sweet cassava cultivars with pink G.A.; Lima, R.S. (2000). Avaliação de cultivares de roots developed by participatory breeding. Crop mandioca na região noroeste do Paraná. Bragantia Breeding and Applied Biotechnology 19(4): 501(59): 69-75. 504.

http://dx.doi.org/10.1590/S0006-

https://doi.org/10.1590/1984-70332019v19n4c73

$\underline{87052000000100011}$

Wheatley, C.C. (1987). Conservación de raíces de

Vieira, E.A.; Fialho, J.F.; Julio, L.; Carvalho, yuca en bolsas de polietileno. Cali: Centro L.J.C.B.; Corte, J.L.D.; Rinaldi, M.M.; Oliveira, Internacional de Agricultura Tropical. 33 p. 